\title{
La cooperación provincial a los servicios municipales: el Plan Provincial de Cooperación
}

\author{
Faustino Martínez Fernández \\ Doctor en Derecho y Licenciado en Ciencias Políticas \\ Diplomado en Administración Local \\ Secretario de la Excma. Diputación Provincial de Lugo
}

Sumario: I. LA PROVINCIA EN LA LEGISLACIÓN VIGENTE. II. CARACTERISTICAS DE LA PROVINCIA. A) La provincia es un ente territorial. B) La provincia es una entidad local. C) La provincia como agrupación de municipios. III. AUTONOMIA Y COMPETENCIA. IV. SISTEMA DE FIJACIÓN DE COMPETENCIAS DE LA LEY 7/85. V. NATURALEZA Y CARACTERES DEL PLAN.

\section{LA PROVINCIA EN LA LEGISLACIÓN VIGENTE}

La organización territorial del Estado sufre un cambio profundo con el advenimiento de la democracia, y sobre todo con la aprobación de la Constitución de 1978.

A riesgo de incurrir en un tópico, se puede decir que un modelo de Estado, unitario, uniformista y centralista, ha dejado paso a otro compuesto, variado y descentralizado.

El modelo territorial de Estado que se configura a partir de la Constitución Española consta de tres escalones: Estado, Autonomías y Entidades Locales. El art. 137 de la C.E. dice expresamente: «El Estado se organiza territorialmente en municipios y provincias, y en las Comunidades Autónomas que se constituyan. Todas estas entidades gozan de autonomía para la gestión de sus respectivos intereses».

En principio pues, podemos decir, que son entes territoriales obligatorios y necesarios según la C.E., el Estado y los entes locales obligatorios (municipio y provincia), puesto que las Comunidades Autónomas lo serán en la medida, según la propia Constitución Española, que se constituyan. 
A la Administración Local se refiere el Capítulo II, del título VIII de la Constitución Española, que comprende los artículos 140, 141 y 142. En ellos se recogen solamente, como entes locales, al municipio y a la provincia, lo que les convierte en obligatorios y necesarios, sin perjuicio de que puedan constituirse otros entes locales, pero cuya existencia no será obligatoria constitucionalmente.

De la constitucionalización de la Administración Local, se deduce que los entes necesarios y obligatorios, como son la Provincia y el Municipio, son entes territoriales, que tienen la condición de Administraciones públicas, que para la satisfacción de sus intereses se les dota de personalidad jurídica "propia», en unos casos, "plena» en otros, dotados de autonomía necesaria para el cumplimiento de los fines públicos encomendados, y protegidos con la garantía institucional que ampara la Constitución a la autonomía de los citados entes.

Aunque no es el momento de analizar la evolución del régimen local, y su desarrollo a través del constitucionalismo español del siglo XIX, lo cierto es que la Constitución de 1978 sigue la tradición española iniciada en la Constitución de 1812, de reconocer como instituciones básicas o necesarias de la Administración Local, al Municipio y a la Provincia, lo cual no quiere decir que el tema, la llamada "cuestión Provincial", no volviese a tener actualidad en la discusión parlamentaria de la Constitución de 1978 y aun después, e incluso se puede decir que el tema aunque constitucionalmente esté cerrado, en la configuración de la autonomía provincial todavía está sometido a debate.

El tema provincial es uno de los temas, que, contrastando con la situación anterior, ha producido más literatura política y científica ${ }^{1}$, y no

1 - La Provincia, pasado, presente y Futuro. BARAJE CARCELLÉ y A. CIFUENTES CALZADO. Ed. Diputación de Cádiz. 1985.

- «Las Provincias». L. MORELL OCAÑA. Tratado de Derecho Municipal, dirigido por S. MUÑOZ MACHADO. Ed. Civitas. 1988. Tomo I.

- «La Provincia en el Régimen Local Español. Evolución y concepto vigente». LUIS MORELL OCAÑA. Régimen Local Español. E. Civitas. Madrid. 1988.

- Las Diputaciones Provinciales en España. J. A. GONZÁLEZ CASANOVA. Madrid 1988.

— «Presente y Futuro de las Diputaciones Provinciales». R.E.D.A. n. ${ }^{\circ}$ 39. S. MARTÍN RETORTILLO.

- "La Provincia en el Régimen Local español». Problemas actuales del Régimen Local. Sevilla. 1958. E.G. ENTERRIÁ.

— «Autonomía Provincial: Diputaciones y proceso autonómico». R.E.A.L.A. n. ${ }^{\circ}$ 248-1990.

S. MARTÍN RETORTILLO.

- La Provincia en el sistema constitucional. Dirigido por GÓMEZ-FERRER MORANT.

Civitas. 1991. Madrid. 
poca abundante jurisprudencia tanto del Tribunal Constitucional, como del Supremo y Audiencias Territoriales, como tendremos ocasión de examinar.

En definitiva, como dice S. Martín Retortillo 2 la provincia ha tenido, pues, un reconocimiento constitucional riguroso y definido, hasta el extremo que no deja lugar a dudas. La Constitución se refiere a ella cuando dice en el art. 137: «El Estado se organiza territorialmente en municipios, en provincias y en las Comunidades Autónomas que se constituyan. Todas estas entidades gozan de autonomía para la gestión de sus respectivos intereses»; y en el art. 141 cuando dice: La provincia es una entidad local con personalidad jurídica propia, determinada por la agrupación de municipios y división territorial para el cumplimiento de las actividades del Estado. Cualquier alteración de los límites provinciales habrá de ser aprobada por las Cortes Generales mediante ley orgánica. El gobierno y administración autónoma de las provincias estarán encomendados a Diputaciones u otras Corporaciones de carácter representativo".

La Ley 7/85 de Bases del Régimen Local al desarrollar la Constitución Española, después de decir en el art. $1 .^{\circ}$ que la Provincia goza de autonomía para la gestión de sus respectivos intereses, autonomía garantizada constitucionalmente (art. $2 .^{\circ}$ ), dice en el art. 31 que la provincia es una entidad local con fines propios y específicos.

\section{CARACTERÍSTICAS DE LA PROVINCIA}

Nos dice G. Casanova 3, que la Constitución de 1978 ha asumido diversas concepciones históricas respecto de las provincias. En la C.E. se sigue considerando a la Provincia como división para la prestación de servicios estatales, pero al mismo tiempo se sigue considerando a la Provincia como entidad local, pero dotada de autonomía, institucionalmente reconocida. A ello hay que añadir un dato nuevo, que hace su aparición en la Constitución que son las Comunidades Autónomas, con competencias sobre régimen local, y por lo tanto sobre la Provincia, lo cual ha complicado el panorama existente, entrando dichos entes en

\footnotetext{
2 S. M. RETORTILLO.- «Autonomía Provincial. Diputaciones y proceso autonómico». R.E.A.L.A. n. ${ }^{\circ} 248-90$.

"El tema de la Autonomía Provincial y Proceso autonómico». La provincia en el sistema constitucional. Civitas-Madrid 1991.
}

${ }^{3}$ G. CASANOVA: Las Diputaciones Provinciales en España. Madrid.1986. 
muchos casos, en franco enfrentamiento, poniendo en peligro la propia existencia en algunos casos, y el normal desarrollo de su actividad en no tan pocos casos, incluso en supuestos en que la diversidad política no podía utilizarse como disculpa.

Podemos, pues, sintetizar las características de la Provincia de la siguiente manera:

\section{A) La provincia es un ente territorial}

Como tal ente es un elemento de la organización territorial del Estado, pues no otro significado tiene la dicción del art. 137 de la Constitución Española, de que el Estado se organiza territorialmente en municipios, en provincias, y en las Comunidades Autónomas que se constituyan.

La jurisprudencia así lo ha reconocido en las ocasiones que ha tenido ocasión de hacerlo:

— La Sentencia del Tribunal Constitucional 4/81, ya señalaba que:

«Los órganos generales del Estado no ejercen la totalidad del poder público, porque la Constitución prevé, con arreglo a una distribución vertical de poderes, la participación en el ejercicio del poder de entidades territoriales de distinto rango".

— La Sentencia del Tribunal Constitucional 84/82 dice:

«Este carácter bifronte del régimen jurídico de las entidades locales en algunas comunidades autónomas que hace imposible calificarlo de forma inequívoca de "intracomunitario" o "extracomunitario", no es contradictorio con la naturaleza que a las entidades locales atribuye la Constitución, cuyo art. 137 concibe a los municipios y a las provincias como elementos de división y organización del territorio del Estado».

- La Sentencia del Tribunal Constitucional 241/89 dice también:

«El carácter bifronte del régimen local posibilita, antes bien, fórmulas cooperativas como la que ahora se analiza, en cuanto que las entidades locales, forman también parte de la organización territorial del Estado. 
- La Sentencia del Tribunal Supremo de 11 de noviembre de 1991 (Sala 3.a, Sección 4.a), se reafirma en esa postura, diciendo textualmente:

«La Constitución Española prefigura una nueva ordenación territorial, que implica, como primera consecuencia, una distribución vertical del poder público entre entidades de distinto nivel, no pudiendo predicarse del Estado, en la actualidad, el ejercicio del poder público, entendido como un todo, porque la Constitución Española prevé con arreglo a una distribución vertical de poderes la participación en el ejercicio del poder de entidades territoriales de distinto rango, tal y como expresa el art. 137 (cir. T.C., Pleno 11 de febrero 1981, 28 julio 1981; T.S. de 3 de febrero 1987)".

La provincia como división territorial, puede serlo para actuaciones del Estado o para prestación de servicios, como tradicionalmente se ha venido diciendo aunque algún sector de la doctrina ${ }^{4}$, considera solamente válida la primera afirmación.

De ello se hace eco el Tribunal Constitucional en la Sentencia 84/82 cuando dice que:

"Las Provincias, siguen siendo divisiones territoriales para el cumplimiento de la actividad del Estado, y municipios y provincias, como entes dotados de personalidad jurídica propia, pueden ser autorizados por el ordenamiento para asumir a título singular el desempeño de funciones o la gestión de servicios que el Estado proponga transferirlos o delegarlos, y que se corresponden con su ámbito de intereses propios definidos por la Ley».

\section{B) La provincia es una entidad local.}

La configuración de la provincia como entidad local suele unirse al Estatuto Provincial de Calvo Sotelo de 20 de marzo de 1925. Se considera que la encomienda que hacen las leyes de satisfacer intereses "propios», "peculiares», "exclusivos» y demás sinónimos que indistintamente suelen utilizar las Leyes, es la clave para considerar al ente territorial como entidad local.

\footnotetext{
4 BAENA DEL ALCÁZAR.- «La provincia como división territorial». IX Congreso ItaloEspañol de Profesores de Derecho Administrativo. Granada. 1985.
} 
Prescindiendo de otros antecedentes 5 el Estatuto Provincial de 20 de marzo de 1925 (de Calvo Sotelo), configura a la Provincia como entidad local, cuando en el art. $4 .^{\circ}$ dice que corresponde a las Diputaciones Provinciales organizar los servicios propios de la Administración Local, que no sean de exclusiva competencia municipal, así como los que el Estado traspase o delegue a las mencionadas entidades, concluyendo el art. 107 que son competencias de la Diputación regir, administrar y fomentar los intereses peculiares de la provincia.

La Ley de Régimen Local de 24 de junio de 1955, después de decir en el art. 2, que la Provincia es circunscripción determinada por la agrupación de municipios, nos decía en el art. $5 .^{\circ}$ que a las Diputaciones Provinciales les corresponde el Gobierno y administración de los intereses públicos peculiares de su territorio.

La vigente Ley $7 / 85$, desarrollando el art. 139 dice expresamente en el art. 31.1 que «la Provincia es una entidad local con personalidad jurídica propia y plena capacidad para el cumplimiento de sus fines. Siendo fines "propios" y "específicos" los que determina el $n .^{\circ} 2$ del mismo artículo.

La Provincia como entidad local está dotada en el sistema actual de dos características fundamentales: $a$ ) dotada de autonomía y $b$ ) esa autonomía está garantizada constitucionalmente.

\section{a) Autonomía.}

Se entiende por tal, como dice Martín Mateo 6, el desempeño autorresponsable de competencias públicas territoriales, lo que incluye desde luego la potestad reglamentaria.

\footnotetext{
5 Ley 21 de octubre 1868: La Diputación es un cuerpo de funcionamiento permanente, dotado de un núcleo de competencias propias, que abarca todo lo concerniente a la administración civil y económica, propia y exclusiva de la respectiva provincia.

La Ley de 20 de agosto de 1870, en su art. 46 señala que: «Es de exclusiva competencia de las Diputaciones Provinciales, la gestión, el gobierno y dirección de los intereses peculiares de la provincia en cuanto según esta Ley, o la municipal, no correspondan a los Ayuntamientos".

El art. 44 de la Ley Provincial de 1877 dice: «Es competencia de las Diputaciones Provinciales, con arreglo al art. 84 de la Constitución, el gobierno y dirección de los intereses peculiares de la provincia, en cuanto se siga esta Ley o la municipal.

6 R. MARTÍN MATEO: "Garantía Constitucional de las Autonomías». R.E.V.L., n.o 208 , p. 609 y ss.
} 
La Carta Europea de la Autonomía Local, en su art. 3.1 define a la Autonomía Local en el sentido de: «Por autonomía local se entiende el derecho y la capacidad efectiva de las colectividades locales de ordenar y gestionar una parte importante de los asuntos públicos, en el marco de la Ley, bajo su propia responsabilidad y en beneficio de sus habitantes".

Podemos pues calificar la autonomía en nuestro Derecho, de acuerdo con las Leyes, la doctrina y la jurisprudencia por las siguientes notas:

$1^{\text {a }}$ - La autonomía no es soberanía y por lo tanto no es un poder ilimitado, sino limitado (S.T.C. $4 / 81$ y 32/81).

$2^{\cdot a}$ - Se suele decir que es un poder administrativo, mientras que las CC.AA. son un poder político. Opinión que no compartimos y que con Sosa Wagner 7 creemos que es muy difícil sostener, a la vista del art. 25.1 de la Ley de Bases de Régimen Local (Ley 7/85). S.T.S. de 11 de noviembre de 1991, habla de "cierto componente político, que le viene atribuido a la Corporación».

3.a - La autonomía local tiene carácter bifronte al insertarse en el ordenamiento del Estado y de la C.A. pero no en exclusiva. Cuando en la Constitución se invoca al legislador para que dote de competencias a tales entes no se refiere exclusivamente al legislador estatal, sino al de las CC.AA. Ex.: Así se ha expresado también el T.C., S. de 23 de diciembre 1982; S. 214/1989.

$4^{\text {a }}$ - Al legislador ordinario corresponde la fijación de las funciones asignadas a los entes locales, en razón de los intereses de estos. Fija así el legislador las competencias de los entes locales.

Las Bases corresponde dictarlas al Estado, que fijan las competencias que vayan a garantizar esa autonomía. El legislador básico fija esas competencias, y ese mínimo a que hicimos referencia, mínimo competencial, que no puede ser desconocido por el legislador sectorial.

5. a - La garantía institucional de la autonomía se configura como una garantía restringida, en el sentido de carecer las entidades locales de recurso directo ante los tribunales para hacer valer esa garantía (como existe en derecho alemán).

${ }^{7}$ F. SOSA WAGNER: «Los Principios del nuevo régimen local». Tratado de Derecho $\mathrm{Mu}$ nicipal. Tomo I. 
FAUSTINO MARTINEZ FERNANDEZ

Por eso más que un concepto positivo es un concepto negativo de rechazo a las invasiones de la autonomía.

6.a - La autonomía es compatible con los controles puntuales de legalidad (Sent. T.C. 4/81). Asimismo en el sistema actual de distribución de competencias, no existen las competencias exclusivas de la Administración Local, lo que califica una función de local o autonómica es el predominio del interés local o autonómico, pero nunca excluye la intervención de los demás entes.

7.a - Lo que veníamos diciendo de la Autonomía Local, es de aplicación a la Autonomía Municipal y Provincial. Si bien, como el art. 141 reconoce a la provincia "personalidad jurídica propia" y el 140 atribuye al Municipio "personalidad jurídica plena", cierto sector de la doctrina ha visto en la Provincia un cierto carácter administrativo, e incluso en alguna Sentencia se le llama ente meramente administrativo, en contraposición al Municipio.

\section{b) Garantía constitucional.}

La denominada garantía constitucional de la Autonomía pertenece a un capítulo de un campo más amplio denominado garantía institucional, y que ha sido elaborado por la doctrina alemana, según ha puesto de manifiesto Sosa Wagner ${ }^{8}$, alrededor de los comentarios del art. 28 de la Ley Fundamental de Bonn.

El tema se recibe en la doctrina española, a través de autores como R. Martín Mateo 9, L. Parejo 10, Embid Irujo ${ }^{11}$, Sosa Wagner 12, G.

\footnotetext{
8 F. SOSA WAGNER: «La autonomía local». Estudios sobre la Constitución española. Homenaje a G. ENTERRIA. Tomo IV. E. Civitas. Madrid. 1991.

Autores como: SCHMITT (garantía constitucional). V. MUTIUS, KNEMEYER, STERN, BURMEISTER.

${ }^{9}$ R. MARTÍN MATEO.— «Garantía constitucional de las Autonomías». R.E.V.L.. n. ${ }^{\circ} 208$.

10 L. PAREJO ALFONSO.- Garantía institucional y autonomía local. I.E.A.L. Madrid. 1981.
}

11 EMBID IRUJO.- «Autonomía municipal y Constitución: Aproximación al concepto y significado de la declaración constitucional de autonomía local». R.E.D.A. n. ${ }^{\circ} 30,1981$, p. 463.

12 F. SOSA WAGNER.- obra citada. 
Enterría ${ }^{13}$, y adquiere gran difusión a partir de la publicación de la Ley $7 / 85$ de las Bases de Régimen Local, texto que se inspira, en cuanto al concepto de autonomía en la doctrina que hemos enumerado anteriormente.

La garantía de esa autonomía (art. 140 C.E.) se recoge en el art. 2 de la Ley de Bases de Régimen Local cuando dice que para la efectividad de la autonomía garantizada constitucionalmente a las entidades locales, la legislación del Estado y la de las Comunidades Autónomas deberá asegurar a los municipios, a las provincias y a las islas su derecho a intervenir en cuantos asuntos afecten directamente al círculo de sus intereses.

La autonomía no se configura así como un derecho fundamental que hay que asegurar constitucionalmente, sino que se configura como una técnica para proteger a los entes locales de que el legislador respetará el círculo de intereses de los entes locales, círculo de intereses que no son más que aquéllos que la sociedad espera que satisfaga como propios.

Qué es lo que constituye núcleo esencial de la autonomía que hay que preservar, es contingente y variable en cada momento histórico, y viene a plasmarse en las competencias que la Ley encomienda a las entidades locales.

\section{C) La provincia como agrupación de municipios.}

Prescindiendo de los antecedentes históricos del siglo XIX ${ }^{14}$, ya la exposición de motivos del Estatuto Provincial ${ }^{15}$ decía que la Provincia como circunscripción de la vida local, tiene su raíz y cimientos en los municipios, por lo que ha de reconocerse a estos el derecho de intervenir primariamente en la Administración provincial. Es lógico, —continúa diciendo el Estatuto- que el municipio órgano político, pueda de-

13 G. DE ENTERRÍA.- La provincia en el sistema constitucional. E. Civitas. Madrid, 1991. Dirección de GÓMEZ-FERRER.

${ }^{14}$ Ley de 20 de agosto de 1870 .- art. $2 .^{\circ}$ : "La provincia se compone de todos los términos municipales dentro de sus límites".

Ley de 2 de octubre de 1877.- "La Provincia se compone de todos los términos municipales comprendidos dentro de sus límites"

15 Gaceta de Madrid n. ${ }^{\circ} 80$, pág. 1447. 
FAUSTINO MARTINEZ FERNANDEZ

terminar la contextura de la provincia, circunscripción administrativa. Desde ahora los municipios serán fuerza prima y alma mater, y la Diputación institución contingente destinada a estimular y complementar las energías municipales.

La Ley de Régimen Local de 24 de junio de 1955, vigente hasta la aprobación de la Ley $7 / 85$, en su art. 1. decía que el Estado español se halla integrado por las entidades naturales que constituyen los municipios, agrupados territorialmente en provincias», completando el art. $2 .^{\circ}$ del mismo texto legal, que la Provincia es circunscripción determinada por la agrupación de municipios, y concluyendo el art. 204 con la división del territorio nacional en provincias, formadas por agrupación de municipios.

En el mismo sentido se expresa el art. 141 de la Constitución Española cuando dice que la provincia es una entidad local con personalidad jurídica propia determinada por la agrupación de municipios, y el art. 31 de la Ley de Bases de Régimen Local recogiendo el texto constitucional, sigue la misma doctrina, al decir que la Provincia es una entidad local determinada por la agrupación de municipios.

\section{AUTONOMIA Y COMPETENCIA}

Tanto la Constitución (art.137) como la Ley de Bases de Régimen Local (arts. 1 y 2) como venimos diciendo, conceden al municipio y a la provincia, autonomía, con una finalidad, para satisfacer sus propios intereses.

Como dice S. M. Retortillo ${ }^{16}$, el concepto de interés se identifica con el de competencia, entendida ésta en el sentido que lo hace Parada 17 de considerar a la competencia como la medida de la capacidad de un ente, siendo el conjunto de funciones y potestades que el ordenamiento jurídico atribuye a cada ente autorizado y obligado a ejecutarlas.

Indudablemente hoy no se puede hablar de intereses exclusivos locales o estatales, siendo mas exacto hablar de interés predominante. Partiendo de la identificación de interés y competencia, que recoge la

\footnotetext{
16 S. MARTÍN RETORTILLO._Obra citada «La autonomía provincial...»

17 PARADA VÁZQUEZ.-Derecho Administrativo. Ed. Pons. 2. a Ed. Madrid 1987.
} 
jurisprudencia del Tribunal Constitucional en la Sentencia $27 / 87^{18}$, es posible fijar competencias con base en el interés predominante, que aunque no sea exclusivo, respeta la autonomía.

La identificación del interés predominante local da origen a lo que tradicionalmente se ha denominado competencias propias ${ }^{19}$, distintas de las delegadas, o competencias como entes autónomos en palabras de Ortega Alvarez ${ }^{20}$, que aunque algún sector doctrinal ${ }^{21}$ exige ciertos requisitos abstractos para calificar esas competencias como propias lo cierto es que tales competencias indican la existencia de un poder público, que permiten al ente local decidir en régimen de autorresponsabilidad sobre el sector de cada materia correspondiente a su grado de participación en la gestión de los intereses públicos.

En el mismo sentido se expresa la Sentencia 27/87 del Tribunal Constitucional cuando dice:

"Como este Tribunal ha precisado en varias ocasiones (S.T.C. 4/81), dicha autonomía hace referencia a la distribución territorial del poder del Estado en el sentido amplio del término, y debe de ser entendido como un derecho de la comunidad local a participar a través de sus órganos propios en el gobierno y administración de cuantos asuntos le atañen constituyendo en todo caso un poder limitado que no puede oponerse al principio de unidad estatal».

La configuración concreta de ese interés predominante local, y como consecuencia de ello la atribución de las correspondientes competencias es una cuestión encomendada al poder legislativo. De ello no duda nadie, y así lo ha expresado el Tribunal Constitucional en la tan-

\footnotetext{
18 S.T.C. 27/87. - «La Constitución garantiza la autonomía de las provincias para la gestión de sus propios intereses, encomendando su gobierno y administración a las Diputaciones...".

19 SOSA y DE MIGUEL.- Las competencias de las Corporaciones Locales. I.E.A.L. Madrid 1985.

20 ORTEGA ÁLVAREZ.— «Las competencias propias de las Corporaciones Locales». Tratado de Derecho Municipal. Dirigido por S. MUÑ̃Z MACHADO. E. Civitas. Madrid. 1991.

21 SALAS. - El tema de las competencias. "Instrumentación de las relaciones entre el Estado y la Administración Local desde la perspectiva de la descentralización territorial" en Descentralización administrativa y organización política. Madrid. 1973. Tomo II.
} 
tas veces citada Sentencia $27 / 87$ al decir: «La concreta configuración de la autonomía provincial corresponde al legislador incluyendo la especificación del ámbito material de la competencia de la entidad local, así como las fórmulas o instrumentos de relación con otras entidades públicas, y el sistema de controles de legalidad constitucionalmente legítimos".

A nuestro juicio, sin embargo el legislador ordinario tiene dos limitaciones:

A) La primera limitación de tipo material, consistente en el respeto a la autonomía, garantizada en la Constitución Española, pero que no se define, y en donde tiene cabida el concepto o la opinión que el pueblo tenga de la institución, en este caso provincial, y en cualquier caso la fijación de un mínimo competencial, que constituya el núcleo esencial de esa autonomía.

Esa limitación la respeta el legislador en el art. 2 de la Ley de Bases de Régimen Local, como mínimo competencial a respetar por el legislador sectorial, mínimo que se fija en la necesidad de intervenir en cuantos asuntos afecten directamente al círculo de sus intereses.

B) La segunda limitación está constituida por lo que la doctrina 22 denomina interpretación funcional de la Ley, cuyo valor no viene dado por la mayor o menor jerarquía sino por la idea de función que cumplen determinadas leyes dentro del ordenamiento jurídico. La Constitución consagra la autonomía local; la Ley 7/85 la desarrolla, y por lo tanto sólo la Ley de Bases de Régimen Local, puede incidir en esa autonomía, ampliándola o restringiéndola; pero ninguna otra Ley sectorial podrá incidir en ese campo.

\section{SISTEMA DE FIJACIÓN DE COMPETENCIAS DE LA LEY 7/85}

Como sabemos, para la Constitución existe solamente un ordenamiento local, dotado de unas características específicas e internamente articulado en dos niveles: municipio y provincia. De la doble circunstancia de la inexistencia de intereses locales por naturaleza y de la con-

22 R. GÓMEZ-FERRER MORANT: «Relaciones entre leyes: competencia, jerarquía y función constitucional». R.A.P., n. ${ }^{\circ} 113-1987$, pág. 7 y ss. 
sistencia de la Administración local en una gestión administrativa de asuntos públicos cumplida democrática y no burocráticamente, se infiere la imposibilidad de una diferencia neta entre intereses municipales y provinciales.

La caracterización de la instancia provincial desde el punto de vista constitucional y en la Ley $7 / 85$, como agrupación de municipios conduce a la conclusión de que desde el ordenamiento general, la articulación interior del específico y autónomo local, no como una discriminación cualitativa de intereses, y por lo tanto, potencialmente de asuntos o competencias «sino mas bien como una diferenciación de las funciones a cumplir respecto de un mismo asunto de interés, y consecuentemente de competencias».

Esta articulación juega para la Constitución, y los ordenamientos jurídicos superiores como garantía de eficacia (art. 103 de la C.E.) en la actuación de competencias descentralizadas en la Administración Local.

Tal construcción, tiene que tener necesariamente repercusión, tiene que manifestarse en la identidad de los intereses que cabe imputar a la Provincia, así como en el diseño funcional de ésta, tales intereses no pueden ser otros que los municipales interesados en aquélla, por lo que la gestión de los mismos solo puede traducirse en función inter o supramunicipales.

Esta construcción, la provincia, es mayoritaria por otra parte en nuestra doctrina ${ }^{23}$ desde que G. Enterría ${ }^{24}$ nos dijo que la «provincia tiene como competencia, precisamente los servicios municipales, aunque se plantee desde la perspectiva de la supramunicipalidad».

De esa forma se comprende que la Ley $7 / 85$, enumere detalladamente las competencias municipales desde un punto de vista material, como se hace en el art. 25, que contrasta con la enumeración parca y po-

\footnotetext{
${ }^{23}$ L. PAREJO: «La provincia como entidad local». En La Provincia en el sistema constitucional. E. Civitas. Madrid 1991.

JOSÉ SUAY y RINCÓN: «La competencia de coordinación». Misma obra anterior.

CLIMENT BARBERA: "La cooperación estatal y autonómica» en Los servicios municipales. Tratado dirigido por S. MUÑOZ MACHADO. Civitas. 1991. Tomo II.

24 G. ENTERRÍA: «La Provincia en el Régimen Local español». En Problemas actuales del Régimen Local. Ed. I. GARCIA OVIEDO. Sevilla 1958.
} 
co concreta que hace el art. 36 para la provincia, sistema criticado desde algún sector doctrinal ${ }^{25}$, precisamente porque las competencias son las mismas.

Para finalizar esta alusión al sistema de fijación de competencias de la Ley $7 / 85$, e íntimamente relacionado con él, nos encontramos con que la Ley, siguiendo por otra parte una tradición histórica en la legislación local 26 diferencia de las competencias generales las competencias mínimas u obligatorias 27 o espacio competencial de carácter nuclear ${ }^{28}$ para Parejo, con la diferencia, de que en el texto actual solo se hace esa distinción con relación al municipio, porque la Ley es consecuente con el concepto de provincia a que nos hemos referido anteriormente.

Pero ello no quiere decir que la distinción no tenga validez alguna con relación a las Provincias, antes bien, como veremos más adelante va a ser una de las competencias más importantes de la entidad provincial.

La distinción en el sistema actual, supone la existencia de un derecho en manos de particular en el caso de los servicios, y por lo tanto, va mas allá de la simple potestad del establecimiento de servicios, nunca negada a la Administración. A ello se inclinan autores como Parada 29, Sosa Wagner 30 o Quintana 31 , y se enumeran entre los derechos de los vecinos en el art. 18.1 G) de la Ley de Bases del Régimen Local, al decir que entre los derechos de los vecinos se encuentra el de exigir la prestación de los

\footnotetext{
25 LÓPEZ RAMÓN: «Los Servicios públicos propios de la Diputación». En La Provincia en el sistema constitucional. E. Civitas.1991.

26 art. 102 L.R.L. 24 de junio de 1955, con relación a los municipios 245 referente a la Provincia.
}

27 PARADA VÁZQUEZ: Op. citada. E. PONS. Madrid 1987.

28 PARADA VÁZQUEZ: Obra citada.

29 PARADA VÁZQUEZ: Obra citada.

30 F. SOSA WAGNER: Gestión de los servicios públicos locales. E. Civitas. 1992. Madrid.

31 T. QUINTANA LÓPEZ: El Derecho a la prestación de los servicios municipales obligatorios. Madrid. 1987. "Justicia administrativa, medio ambiente y servicios municipales». REDA. n. ${ }^{\circ} 65.1990$. 
correspondientes servicios obligatorios 32 , y así lo ha entendido la jurisprudencia del Tribunal Supremo en Sentencias, entre otras, de 9 de mayo de 1986, y 25 de Abril de 1989 (Sala 3.a. Ponente, González Navarro).

En la especial protección que la Ley da a los derechos de los ciudadanos en relación con los servicios obligatorios, es donde hay que situar la especial competencia que con relación a los mismos tiene la Provincia. Si el art. 31.2 a) señala entre las competencias provinciales la de asegurar la prestación integral y adecuada en la totalidad del territorio provincial de los servicios de competencia municipal, el art. 36.2.b) impone a las Diputaciones la obligación de asegurar el acceso de la población al conjunto de los servicios mínimos de competencia municipal, pudiendo incluso sustituir al municipio en la prestación de los mismos, como dice G. Navarro ${ }^{33}$, y debiendo de hacerlo con la aprobación del Plan Provincial de Obras y Servicios.

\section{Síntesis Histórica.}

Los Planes de cooperación, que con un nombre u otro, tienen siempre la finalidad de implantar o desarrollar los servicios municipales, están muy ligados al nacimiento del concepto de Provincia como ente formado por agregación de municipios, como tuvimos ocasión de examinar anteriormente.

Uno de los avances legislativos más significativos sobre el tema que tratamos se dió por la Ley de Bases de Régimen Local de 17 de julio de 1945, que en su base 43 dispuso que las Diputaciones Provinciales cooperasen a la realización de los servicios mínimos municipales con los Ayuntamientos de la Provincia, cooperación que se regula posteriormente con más detalle en el texto articulado de la Ley de 16 de diciembre de 1950, de los arts. 255 al $258{ }^{34}$.

\footnotetext{
32 Art. 18.1.6 de la Ley 7/85: Son derechos y deberes de los vecinos: 1.6., «Exigir la prestación, y en su caso el establecimiento del correspondiente servicio público en el supuesto de constituir una competencia municipal propia de carácter obligatorio».

${ }^{33}$ F. GONZÁLEZ NAVARRO: «Delegación, Sustitución y Avocación» en la Nueva legislación local. Cap. V, p. 260. Tratado de Derecho Local, dirigido por S. MUÑOZ MACHADO. E. Civitas. Madrid.1989.

34 Art. 255: "La Provincia cooperará a la efectividad de los servicios municipales, principalmente los obligatorios, que no puedan ser establecidos por los Ayuntamientos, y recibirá para ello del Estado la ayuda financiera a que aluden los arts. siguientes».
} 
La cooperación provincial se instituye, pues, en la forma que hemos visto, diciendo algún sector de la doctrina, como Carmelo Abellán 35 que la institución de la cooperación provincial a servicios mínimos municipales, sirvió para dar contenido a las Diputaciones Provinciales que hasta el momento llevaban una vida lánguida prestando servicios de beneficiencia y comunicaciones de la Provincia.

La financiación de la cooperación se establece en la Ley de Bases de Haciendas Locales de 3 de diciembre de 1953, que crea el arbitrio sobre riqueza provincial, debiendo de dedicar a la función cooperadora una cuantía de ese arbitrio que anualmente fijaría el Ministerio de Gobernación, refiriéndose solo a municipios inferiores a 20.000 habitantes, y núcleos de población de otros mayores separados del casco y de escasa densidad.

El texto refundido de la Ley de Régimen Local, de 24 de junio de 1955 , vigente casi en su totalidad hasta la publicación de la Ley $7 / 85$, dedica la Sección 3.a del Capítulo Primero, del título II, a la cooperación provincial a los servicios municipales.

La Diputación, decía el art. 255, cooperará a la efectividad de los servicios municipales, principalmente de los obligatorios, que no puedan ser establecidos por los Ayuntamientos.

Para el desarrollo de la cooperación redactarán las Diputaciones, oídos los Ayuntamientos, planes bienales ordinarios que se ejecutarán anualmente.

Los servicios a que se dirije la cooperación son los obligatorios, que en el apartado $3 .^{\circ}$ del art. 255 se identifican como servicios mínimos a los que se refieren los art. 102 y 103 de la Ley de Régimen Local. La preferencia de estos servicios es contundente al decir la Ley «en todo caso", como servicios a los que se extiende la cooperación.

Pero la Ley, en el apartado $4 .^{\circ}$ del mismo artículo va más allá, y quizás reconociendo la imposibilidad de que un solo plan

Art. 256: "Cuando los municipios no pueden establecer con sus propios recursos los servicios obligatorios, incluyendo los de incendios y suministro de energía eléctrica, la Provincia los instalará y los Ayuntamientos contribuirán a los gastos de establecimiento con la cantidad que corresponde a la capacidad de crédito de cada una de las entidades municipales interesadas".

35 CARMELO ABELLÁN: Tratado Práctico de la Administración Local Española. Tomo I. Madrid 1971. I.E.A.L. 
dote a los municipios de los servicios mínimos exigidos, señala un orden de preferencia ${ }^{36}$.

El Reglamento de Servicios de las Corporaciones Locales de17 de junio de 1955, dedica el título IV con sus cuatro capítulos a la cooperación provincial a los servicios municipales, comenzando por decir, incluso de forma más contundente que la Ley, en el art. 156, que las Diputaciones Provinciales y Cabildos Insulares tendrán la misión obligatoria e inexcusable de cooperar a la efectividad de los servicios municipales, estableciendo el art. 162, la misma preferencia que vimos hacia el art. 255.4 de la Ley, pero sin apartado k).

El procedimiento, según presenta el art. 163, las Diputaciones redactarán el Plan, oídos los Ayuntamientos; pero no los aprueban definitivamente, puesto que esto lo hacen las Comisiones Provinciales de Servicios Técnicos.

Las formas de cooperación, coinciden sustancialmente con las enumeradas en el art. 255.6 de la Ley y el art. 160 del Reglamento de Servicios ${ }^{37}$.

A partir de 1958, las Diputaciones Provinciales, en lo referente a Planes Provinciales, van siendo desplazadas por los Planes de Inversiones Provinciales, financiados por el Estado (Decreto del 13 de febrero de 1958, dictado en aplicación de la Ley de Presupuestos Generales del Estado de 26 de diciembre de 1957, y de la Orden de 13 de marzo de 1958). De esta forma la cooperación provincial (Diputaciones), queda subordinada a los Planes Estatales, y se desvía la finalidad inicial de la cooperación que iba dirigida a municipios inferiores a 20.000 hts. ${ }^{38} \mathrm{o}$ núcleo rurales o pequeños núcleos de población.

\footnotetext{
36 Art. 255.4: «La preferencia será la siguiente:

a) abastecimiento de aguas potables, abrevaderos y lavaderos; b) alcantarillado; c) alumbrado público; d) botiquín de urgencia; e) sanitarios e higiénicos en general; f) matadero; g) mercado; h) extinción de incendios; i) campos escolares de deportes; j) cementerios; k) los demás no expresados anteriormente, y comprendidos en dichos artículos de la Ley (102 y 103).
}

37 255.6, L.R.L.: «Las formas de cooperación serán:

a) orientación económica y técnica; b) ayudas de igual carácter en la redacción de estudios y proyectos; c) subvenciones a fondo perdido; d) ejecución total de obras e instalación de servicios; e) anticipos económicos de carácter reintegrable; f) creación de cajas de crédito para facilitar a los Ayuntamientos operaciones de préstamo a corto plazo; g) cualesquiera otras que apruebe el Ministerio de la Gobernación".

38 art. 161. Reg. Servicios: 1. La cooperación provincial alcanzará a los municipios de menos de 20.000 hts. y se referirá normalmente a los municipios rurales, y a los pequeños núcleos de población. 
Esta disparidad de criterios sobre ayuda a prestar a los municipios y a cuales de ellos, no tendría trascendencia para la cooperación provincial, si no hubiera surgido del citado Decreto de Febrero de 1958, que dispuso que los Planes Provinciales, que, como vimos, financiaba el arbitrio sobre la riqueza provincial, se coordinarán con los planes de inversiones, y la Orden de la Presidencia de 29 de marzo del mismo año, motivó que en muchas provincias, las Diputaciones orientasen la Cooperación a facilitar a los Ayuntamientos, incluidos en los Planes de Inversiones, las sumas necesarias para cubrir las aportaciones de los municipios, con lo que la cooperación queda desvirtuada, al desviarse las inversiones a los servicios que el Estado eligiese sin tener en cuenta los "mínimos" u "obligatorios" y sin tener en cuenta la finalidad de ayudar a los municipios menores de 20.000 hts. o rurales.

La recuperación de la competencia Provincial en lo que venimos estudiando sobre Planes de Cooperación a los Servicios Municipales, se produce con la promulgación del R.D. $688 / 78$ de 17 de febrero. A tal fin, y de conformidad con el art. 1.1. se elaborará un plan único de Obras y Servicios, de carácter provincial, que afecte a municipios de población inferior a 20.000 hts., precisando el art. 1 del R.D. 1779/78 de 15 de julio, que el Plan de Obras y Servicios a que se refiere el art. 1, número 1 del R.D. 688/78 de 17 de febrero "comprenderá los antiguos Planes de Servicios Técnicos, Planes de Cooperación y Planes de Conservación y reparación de caminos vecinales y provinciales, todos los cuales quedan suprimidos".

Los cambios realizados por el R.D. 688/78, son importantes, y muy sustanciales, pudiendo decirse que vuelven en cierto modo a la legislación anterior a 1958, pero incorporando los efectos de una autonomía, que posteriormente consagrarían la Constitución Española y la Ley $7 / 85$.

Se implanta el nuevo Plan único de Obras y Servicios, ciñéndolo con carácter general a los municipios inferiores a veinte mil habitantes, pudiendo incorporarse obras de municipios superiores, previo informe de la Comisión de Colaboración.

La enumeración de las obras a incluir, no guarda relación con la legislación de Régimen Local anterior, ni hace referencia alguna a los

2. Excepcionalmente podrá extenderse a los municipios de más de 20.000 hts. para aplicarla en núcleos rurales, de sus respectivos términos, cuya población no exceda de 10.000 hts. 
servicios mínimos ${ }^{39}$. De la financiación trata el art. $2 .^{\circ}$, pero quizá las innovaciones más importantes se hacen en la aprobación y ejecución de los Planes.

\section{- Mercado de ganado}

En el art. 9. ${ }^{\circ}$, se señala que el estudio, elaboración, aprobación del Plan corresponderá a las Diputaciones Provinciales, en colaboración con los Ayuntamientos y demás entes locales, concluyendo el art. 11 que el Plan Provincial de Obras y Servicios se aprobará por la Diputación Provincial, aprobación que tendrá carácter vinculante para las Diputaciones y para el Estado en la parte subvencionada con fondos del Tesoro.

La ejecución a que se refiere el art. 13 corresponde a la Diputación Provincial, mediante contratación correspondiente de las obras del Plan, salvo que la Diputación la encomiende a los Ayuntamientos y otros entes locales, previa solicitud de los mismos, y correspondiente justificación de tener capacidad de gestión y medios técnicos para ello.

La última etapa legislativa, viene representada por la aprobación de la Ley 7/85, y demás disposiciones de régimen local aplicables. El Plan, que se llamará Provincial de Cooperación a las Obras y Servicios de competencia Municipal viene regulado en el art. 36.2.a), siendo sus innovaciones más importantes, además del nombre, que en realidad no es mas que una exigencia del contenido de los mismos, la referencia a los servicios municipales como único contenido del Plan, siendo el art. 30 del R.D. 781/86, quien declara la preferencia de la cooperación a los servicios mínimos municipales, aunque, como veremos, se podría deducir del n. ${ }^{\circ}$ 2.b) del art. 36, en relación con el 31 de la misma Ley.

El contenido se regula en el art. 36 de la Ley, prescribiendo además la participación de los municipios en la elaboración del mismo, concepto por lo demás de contornos imprecisos como tendremos ocasión de examinar, añadiendo el art. 32.4 del R.D. 781/86 la participación de

39 art. $2 .^{\circ}$ R.D. $668 / 78$ : Servicios:

- Abastecimiento de Aguas y Saneamiento:

- Vías Provinciales y Locales.

- Equipamiento de núcleos, especialmente pavimentación, alumbrado público y servicio de extinción de incendios.

- Electrificación rural.

— Extensión telefónica de áreas rurales. 
FAUSTINO MARTINEZ FERNÁNDEZ

la Administración del Estado y de la Comunidad Autónoma, haciendo preceptivo el informe de la Comisión de Colaboración del Estado con las Corporaciones Locales.

La aprobación sigue siendo competencia de la Diputación Provincial a tenor de los arts. 36.2.a) de la Ley $7 / 85$ y 32.5 del R.D. 781/86, aunque como veremos, desde distintos ángulos se le da a esta competencia un contenido distinto. La ejecución, corresponde a la Diputación, dice el art. 32 del R.D. 781/86 salvo que la contratación sea asumida por los Ayuntamientos; en los supuestos que ejecute la Diputación, una vez recibida la obra, prescribe el último apartado del art. 32, muy coherente con el contenido del Plan, la entrega de la obra o servicio al municipio correspondiente.

La última disposición administrativa referente a Planes Provinciales está constituida por el R.D. $665 / 90$ de 25 de mayo. Si hemos de hacer caso a la exposición de motivos, el Real Decreto se refiere a la cooperación económica del Estado con las entidades locales, que se inspira en los principios de solidaridad y de coordinación entre las distintas administraciones públicas, reordenando los instrumentos de la cooperación económica con las entidades locales, ajustándose a la Ley de Bases de Régimen Local y la Ley Reguladora de las Haciendas Locales; a tal fin el Real Decreto establece de acuerdo con lo dispuesto en el art. 36.2.a) de la Ley $7 / 85$, las condiciones de utilización y empleo de las subvenciones estatales.

Si hemos de hacer caso al Ministro para las Administraciones Públicas, en sus declaraciones a la Voz de Galicia 40 de lo que se trata es de una cosa bien distinta. Dice el Ministro que el M.A.P. podría «vetar», en algún programa de inversión de una Diputación Provincial; a partir del próximo año será el M.A.P. quien controle los proyectos de inversión cofinanciados por el Estado, llegando el Sr. Ministro a poner un ejemplo muy ilustrativo, a juicio del Periodista: «Si por ejemplo una Diputación de Galicia - Comunidad en la que un $13 \%$ de los hogares no tiene agua potable- no incluye entre sus proyectos esta necesidad, no se concederá la subvención, o recibirá el dinero, solo si cambia de Plan». "Hasta ahora, eso no se podía hacer, y queremos que se consiga erradicar esas carencias de algunos municipios" 41 . Huelgan los comentarios sobre tan ilustrativos textos, del máximo responsable del Real Decreto 665/90.

40 Voz de Galicia, 30 de mayo de 1990

41 La cursiva es del periódico. 
Solo nos cabe añadir, para concluir, que nada nuevo aporta esta disposición a la figura de los Planes, a no ser su intento de control, y cercenamiento de la autonomía provincial, sobre todo en su art. $7 .^{\circ} .242, y$ sobre todo en el art. $8 .^{\circ} 43$, que a nuestro juicio es ilegal por atentar contra la autonomía provincial tal como la perfila la doctrina constitucional. Pero sobre ese tema volveremos en otra ocasión.

\section{NATURALEZA Y CARACTERES DEL PLAN}

Nos dice Lliset Borrel ${ }^{44}$ que el plan provincial de cooperación con las obras y servicios de competencia municipal, es un plan asistencial, de fomento de la actividad municipal, colocado en un nivel intermedio entre un plan autonómico de coordinación de las actividades provinciales de cooperación y las actividades municipales a las que coopera (planificado o no, a nivel municipal).

Sin perjuicio de aceptar esta definición como válida, por nuestra parte, creemos que el Plan Provincial, en realidad aunque el Plan se llame de cooperación, son los principios de cooperación y coordinación quienes informan el Plan y que al incidir en el mismo, adquieren una dimensión especial, como veremos va más allá del fomento de la actividad municipal, pudiendo llegar a sustituirla, como veremos en su momento, para lo cual añadiríamos a la definición antes citada de fomento de la actividad municipal, o en su caso, de prestación de obras y servicios.

Son características del Plan, a nuestro juicio:

a) El plan es provincial, haciendo referencia a que la competencia para su aprobación es de las Diputaciones Provinciales. Ni que decir

42 art. 7. . 2: «Los Planes Provinciales de Cooperación, una vez cumplimentadas todas las exigencias legales de publicidad y tramitación, y con carácter previo a su aprobación definitiva, serán remitidos al Ministerio para las Administraciones Públicas, con la solicitud de subvención, y la relación de prioridades establecida por la propia Diputación, antes del 15 de diciembre del año anterior al de su ejecución".

43 El Ministerio para las Administraciones Públicas analizará el Plan Provincial de cooperación a fin de acordar su participación en la financión del mismo de acuerdo con las previsiones del Programa de Cooperación económica local, de la adecuación del Plan al mismo y de lo establecido en este Real Decreto.

44 LLISET BORREL: Los Planes Sectoriales de Coordinación interadministrativa de la actividad local. E. Diputación de Barcelona. 1990, p. 80. 
tiene que en él intervienen participando los municipios y el Estado, obligatoriamente y las Comunidades Autónomas. Pero la competencia para la aprobación, repetimos, es provincial, siendo una competencia esencial en la configuración de la Autonomía provincial.

b) Es un plan de cooperación, si bien como veremos, la cooperación, juntamente con la coordinación adquiere en el Plan una dimensión especial.

c) Es un plan, cuyo contenido se refiere a servicios municipales, fundamentalmente los mínimos u obligatorios, sobre los cuales pesa sobre las Diputaciones el deber de garantizar a los vecinos la prestación integral de los mismos.

\section{El Plan es Provincial}

Decimos que el Plan es provincial, porque la aprobación del mismo es una competencia provincial. Competencia que reviste unas especiales características, en torno a la cual se articula una de las bases de la autonomía provincial. El hecho de que en el mismo intervengan municipios y el propio Estado además de las Comunidades Autónomas, nos obliga a deslindar los campos competenciales de cada uno de los sujetos intervinientes, aunque sea someramente.

La cooperación y coordinación al incidir en el Plan Provincial, adquieren una dimensión especial, y convierten al Plan en una competencia distinta de la cooperación y la coordinación no incidentes en el Plan 45. Como veremos más adelante, el Tribunal Supremo considera el art. 36 de la Ley, en cuyo apartado $2 .^{\circ}$ a) se señala la competencia de aprobar el Plan Provincial, como haz mínimo de competencias, que configuran la autonomía provincial.

Así planteadas las cosas, vamos a ver las distintas fases, por las que atraviese el Plan hasta su ejecución, y el deslinde de las competencias, primero del municipio y luego del Estado y de la Comunidad Autónoma:

a) Elaboración.- Es una competencia provincial. Así lo expresa el art. 36.2.a), y el art. 32.1 del Real Decreto 781/86, aunque éste utiliza la palabra redactar.

45 CLIMENT BARBERÁ: “La cooperación estatal y autonómica a los servicios municipales». Tratado de Derecho Municipal, dirigido por S. M. MACHADO. Civitas. 1989. 
En esta fase la intervención de los Ayuntamientos se refiere a que habrán de participar, así lo dicen los arts. 36.1.a) y 32.4 aunque éste lo extiende al Estado y Comunidad Autónoma.

La competencia municipal, no es una propuesta, sino solamente una participación, una competencia que va mas allá del deber de intervenir en cuantos asuntos le atañen del art. 2 de la Ley de Bases del Régimen Local, pero no llega a tener una competencia de propuesta, entendida, claro está, en sentido jurídico, como parte de la competencia de aprobación, en donde el receptor de la propuesta solo puede aceptarla o rechazarla, pero no sustituir. En este sentido la propia Ley de Bases, en su art. 69.2 nos dice cuales son los efectos de la participación, y que en ningún caso podían menoscabar las facultades de decisión que corresponden a los órganos representativos regulados por la Ley.

b) Aprobación, que se considera competencia exclusiva provincial. $\mathrm{El}$ art. 36, tantas veces citado nos habla de que la Diputación aprobará, y el art. 32.4 del Real Decreto 781/86, nos dice que los planes de cooperación serán aprobados por la Diputación Provincial.

Por lo tanto, ni el municipio, ni el Estado o las Comunidades Autónomas pueden tener competencia alguna en la aprobación de los Planes.

Las Sentencias del Tribunal Superior de Justicia de Galicia (27 de

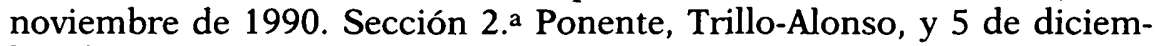
bre de 1990. Ponente, Gómez y Díaz-Castroverde), dicen expresamente que la aprobación del Plan es competencia de la Diputación, analizando la participación municipal en el plan dicen que no puede considerarse ni una propuesta, ni un informe, porque no lo dice así el art. 36.2.a) de la Ley de Bases de Régimen Local; ni tampoco es un informe vinculante por aplicación del art. 85 de la Ley de Procedimiento Administrativo, al no existir precepto expreso en contrario, y tampoco es una competencia municipal, porque no se encuentra entre los enumerados en los arts. 25 y 26 de la Ley de Bases.

Por su parte, el papel del Estado y de las Comunidades Autónomas sobre el plan, no debería de ser distinto al de los municipios, puesto que de la redacción del art. 32.4 del R.D. 781/86, no se infiere otra cosa. "Los planes - dice- de cooperación serán aprobados por las Diputaciones después de haber dado participación a las Administraciones del Estado y Comunidades Autónomas...», que coincide, sustancial y formalmente, con la expresión de «con participación de los municipios» del art. 36.2.a). 
Ello no quiere decir que en unos casos el M.A.P., y en otros las Comunidades Autónomas pretendiesen imponer sus criterios con fórmulas variadas. El análisis de estos problemas nos llevaría fuera de nuestro comentario, aunque no podemos dejar de citar aquí dos sentencias de la Audiencia Nacional de 5 de noviembre de 1991 y 13 de marzo de 1991.

El R.D. 665/89, art. 8. ${ }^{\circ}$, a nuestro juicio ilegal e inconstitucional. Las Sentencias se encuentran pendientes de fallo por el Tribunal Supremo, y el art. 8. $^{\circ}$ del R.D. 665/89, ha sido impugnado, por lo que debemos de esperar las decisiones judiciales al respecto.

Con relación al plan y Comunidades Autónomas, la Sentencia del Tribunal Supremo de 23 de junio de 1989, Sala 3.a. Sección 1. a Ponente, Esteban Alamo ${ }^{46}$ afirma taxativamente que:

«los artículos 36 y 59 de la Ley de Bases de Régimen Local lo que hacen es señalar las competencias de las Diputaciones y de las Comunidades, vertebrándolas en los principios de autonomía y coordinación, con origen en la Constitución, impugnan toda la normativa de Régimen Local para asegurar la coherencia de la actuación de las Administraciones Públicas en el ámbito de la cooperación, asistencia, y en definitiva, solidaridad entre las mismas, pero siempre sin menoscabo de su autonomía".

Estamos así, dice Ortega Alvarez ${ }^{47}$ ante una reafirmación del principio de autonomía, que debe de existir como núcleo esencial del Régimen Local.

La Sentencia del 1 de septiembre de 1990 (Sala 3.a. Sección 6.a. Ponente, Barrio-Iglesias), nos dice que el art. 36 configura el haz mínimo de competencias de la autonomía provincial reconocida en el art. 137 de la Constitución Española. La Diputación no puede ser privada de esas facultades decisorias en este ámbito de actuación porque ello supondría privarle de su propia autonomía garantizada constitucionalmente.

46 CARBALLEIRA RIVERA Y FERREIRA ÁLVAREZ: «Plan único de Obras y Servicios y autonomía local" (S.T.S. de 26 de junio de 1991.R.E.A.L.A. n. ${ }^{\circ} 248.1990$.

47 ORTEGA ÁLVAREZ: El Plan Unico de Obras y Servicios de Cataluña y la garantía institucional de la Autonomía Provincial. Ed. Cuadernos Civitas. Madrid, 1992. 
Deja a salvo las competencias coordinadoras de las Comunidades Autónomas, y entre ellas la de coordinar los propios Planes Provinciales, pero en cualquier caso han de respetar un mínimo competencial que da contenido a la autonomía provincial.

c) La ejecución del Plan. Dice la regla 2.a del art. 33 del R.D. 781/86, que corresponde a la Diputación Provincial, sin perjuicio de la posibilidad de que la asuman los municipios afectados, siempre que así lo soliciten. Nos parece que existe una diferencia sustancial con la legislación anterior en donde la Diputación delegaba en los Ayuntamientos, con el cumplimiento de ciertos requisitos, que ella apreciaba, y al ser la delegación un acto volitivo podía ser condicionado y en definitiva dirigido por dicha entidad. A partir del Real Decreto 781/86, la situación, creemos que ha cambiado radicalmente, puesto que a los Ayuntamiento les basta con asumir la ejecución, mediante la correspondiente solicitud; en tal sentido, se puede decir que la potestad de ejecutar los planes, que antes tenían las Diputaciones, pudiendo delegarla, ha pasado a los municipios, quienes podrían no asumirla, en cuyo caso corresponde la ejecución a la Diputación correspondiente.

\section{Plan de Cooperación}

La segunda característica de los Planes es que lo son de cooperación a servicios municipales. Ello nos exige que sentemos unas premisas previas sobre los conceptos de cooperación y afines, para tratar de delimitar el principio y su aplicación a los Planes Provinciales.

La definición de cooperación, en sentido gramatical, nos ilustra muy poco sobre el concepto jurídico del término. Cooperar es realizar algo conjuntamente por parte de dos sujetos con competencia para ello; en este sentido encontramos la primera diferencia del principio de coordinación, con quien se halla unido en esta competencia del Plan Provincial, porque en éste el coordinador es algo externo a las competencias que coordina.

Pero si hemos de destacar una característica del principio de cooperación, que lo diferencia del de coordinación, es la voluntariedad que se da en la cooperación, y la imposición que se da en la coordinación. Así lo ha reconocido el Tribunal Constitucional en Sentencia 214, Fundamento de Derecho n. ${ }^{\circ} 20$, «la voluntariedad en el caso de la cooperación frente a la imposición es por sí un elemento diferenciador de primer orden».

Por otro lado la cooperación es una técnica que admite varias clasificaciones, y que a nuestro juicio podemos agruparlas en: a) coopera- 
ción voluntaria o pactada, que es la cooperación general y en donde la voluntad de los cooperantes es fundamental; sin la voluntad de los sujetos que no se puede dar la cooperación, y a ella alude el art. 57 de la Ley de Bases de Régimen Local; y b) cooperación formalizada o normada, distinta de la anterior, en la que la voluntad de los sujetos no tiene la misma importancia, y que se produce a través del Plan Provincial.

Tanto la cooperación como la coordinación que se dan a través del Plan Provincial convierten a la Provincia en sujeto cooperante que impone servicios sin la aceptación de los municipios, siempre repetimos, que se produzca por el Plan Provincial como acertadamente señala Climent Barbera ${ }^{48}$. Sin embargo la cooperación a servicios supramunicipales será distinta de la anterior.

La consecuencia inmediata de esta concepción es que la Diputación puede, con diversos condicionantes, sustituir la voluntad municipal por la suya en la determinación de cuáles son las obras a incluir en el plan, en cuya elaboración participan los municipios.

Así lo entendieron las Sentencias del Tribunal Superior de Justicia de Galicia, Sección 2. a en Sentencias:

- 27 de noviembre 1990.- Ponente, Ilmo. Sr. D. Juan Carlos Trillo Alonso, por discrepar del parecer de la mayoría el que lo era el Ilmo. Sr. D. Gonzalo de la Huerta Fidalgo.

- Sentencia de 5 de diciembre de 1990._ Ponente, Ilmo. Sr. D. José María Gómez y Díaz Castroverde.

Ambas Sentencias tienen un voto particular del Magistrado De la Huerta Fidalgo.

Las relaciones entre Provincia y Municipio deben de explicarse a través de los conceptos de cooperación y coordinación, presentes en el art. 36, ya que el Plan de Cooperación atiende a las finalidades, entre otras del ap. b) del n..$^{\circ} 2$ del art. 36 de asegurar el acceso a los servicios mínimos.

Señalan las Sentencias, que las obras incluídas en los Planes, obviamente, han de ser las de competencia municipal, excluyéndose las su-

48 «La cooperación estatal y autonómica en los servicios municipales». Tratado de Derecho Municipal dirigido por S. M. MACHADO. Madrid. Civitas. 1989. 
pramunicipales, y las de interés provincial, y de las municipales, aquellas que no cuenten con la oposición de un Ayuntamiento en concreto, con base en la voluntariedad que ha de presidir la actuación de cooperación.

Las Sentencias del Tribunal Superior de Justicia de Galicia, de 27 de noviembre y 5 de diciembre de 1990, en sus Considerandos Cuarto y Quinto, dicen:

"Cuarto.- Y es que, en el antes citado artículo 36 LBRL, se utilizan los conceptos de coordinación y cooperación, en los que reside la verdadera naturaleza de las relaciones competenciales entre Diputaciones y Ayuntamientos, singularmente si se tiene en cuenta que el territorio de éstos forma parte de la Provincia, ámbito territorial de aquéllas, y que los Diputados son precisamente Concejales pertenecientes a Municipios de los respectivos territorios.

Así las cosas, el problema surge cuando se parte del dato incuestionable de que las obras y servicios contenidos en los Planes Provinciales de cooperación son precisamente de competencia municipal. Consecuentemente, desde la óptica de negar a los Municipios la previa propuesta de aquéllos, podría plantearse el que la inclusión por la Diputación condujese a una limitación competencial de los municipios incompatible con el régimen ordinario de régimen local y constitucionalmente inaceptable al traducirse, en definitiva, en una subrogación carente de cobertura normativa.

En este caso y como queda dicho, las relaciones deben explicarse a través de los conceptos de coordinación y cooperación, presentes en el artículo $36 \mathrm{LBRL}$, ya que el Plan provincial de cooperación atiende precisamente, y entre otras finalidades, a la coordinación de los servicios municipales entre sí para la garantía de la prestación integral y adecuada a que se refiere el apartado a) del número 2 del artículo 31 .

Entendiendo la cooperación como la conjunta actuación dentro de las respectivas competencias para la consecución de un fin determinado, y siempre teniendo presente la identidad sustancial de elementos personales y territoriales existente entre Diputaciones y Ayuntamientos, un primer límite se establece para la actuación de los Entes provinciales en cuanto, en el Plan objeto de litigio, habrán de quedar excluídas aquellas obras y servicios de exclusivo interés provincial o supramunicipal, residenciándose en éste exclusivamente las de interés municipal. Es precisamente en ese punto donde, eventualmente, podrá 
FAUSTINO MARTINEZ FERNÁNDEZ

producirse el conflicto, ante la discrepancia de ostentar tal carácter la obra o servicio pretendido o, simplemente, la negativa municipal a su realización. Se trata aquí de la oposición a la actuación de la competencia provincial en el terreno de los servicios municipales, precisamente por quien ostenta su titularidad. Pues bien, en este caso, y en sede de cooperación, no puede la provincia decretar la prestación de servicios municipales en contra de la decisión municipal, como se sigue, por lo demás, del carácter voluntarista que otorga a la cooperación el artículo 57 LBRL, debiendo desistir de su propósito en la aprobación definitiva la Corporación provincial que, tras incluir una obra o servicio en el Plan, en vía de cooperación, advierte la oposición del Ayuntamiento respectivo.

Ahora bien, la Diputación (artículos 31.2.a) y 36.1.a) LBRL) no sólo tiene competencia, sino que viene obligada por Ley a asegurar y garantizar la íntegra y adecuada prestación de los servicios municipales, señaladamente los mínimos consignados en el artículo 26.1 LBRL. Tal mandato legal, cuando no es factible a través de la cooperación, puede hacerse efectivo mediante las facultades provinciales de coordinación, en cuanto ordenación común de actividades atinentes a diversos sujetos, facultades contempladas en el artículo 36.1.a) LBRL cuya instrumentación (artículo 36.2) se efectúa mediante los Planes provinciales de cooperación. Es en este supuesto, de insuficiencia o inconveniente prestación de los servicios municipales mínimos, sintéticamente coincidentes con los llamados a incluirse en los Planes (cfr. artículo 1.2 del Real Decreto 1673/81, de 3 de julio), cuando el ámbito de decisión es de la provincia y puede ejecutarse sin la aceptación del Municipio afectado.

Quinto.- Ciertamente ello comporta una exigencia de específica motivación por parte de la Cooperación provincial al aprobar definitivamente el respectivo Plan, en cuanto afecta a la voluntad y actuación de los Municipios afectados, provocando su ausencia la anulabilidad del acto en los términos del artículo 48.2 de la Ley de Procedimiento Administrativo».

Entendemos que los supuestos en que no habiendo petición de una obra por parte de un Ayuntamiento, y se incluye en el Plan, y no hay oposición del Ayuntamiento, la obra puede incluirse en el mismo, y ello, por los siguientes motivos:

a) Porque la voluntariedad que exige el art. 57 de la Ley para la cooperación, no se exige que sea positiva, bastando también la ausencia de oposición. 
b) Porque ello permitiría subsanar la participación de todos los municipios, en caso de la negativa de alguno a participar en el Plan.

c) Porque es obligación de la Provincia asegurar la prestación integral, especialmente en los de menos capacidad económica de los servicios de competencia municipal.

Como consecuencia de la obligación legal de la Diputación de asegurar la íntegra y adecuada prestación de los servicios municipales no por cooperación, pero sí por coordinación instrumentalizada a través del Plan Provincial; en estos supuestos la insuficiencia inconveniente de los servicios mínimos, puede hacerse sin aceptación de los municipios.

Añade la Sentencia que ello supone la existencia de una motivación, como elemento, creemos que esencial, dentro del grupo de las competencias.

La Sentencia del Tribunal Superior de Justicia de Galicia del 12 de octubre de 1991, Ponente, Arrojo Martínez, recoge en general la doctrina sobre planes que se contenía en los votos particulares antes comentados a las dos Sentencias.

La Sentencia del Tribunal Superior de Justicia de Galicia de 8 de Noviembre de 1991. Ponente, DE LA HUERTA FIDALGO, se expresa en el mismo sentido, aunque los fallos son distintos, la doctrina es idéntica.

Ambas Sentencias tienen votos particulares del Ilmo. Sr. TRILLO ALONSO.

$\mathrm{Ni}$ que decir tiene que ambas Sentencias no nos parecen correctas, aunque hayan merecido el comentario ${ }^{49}$ favorable de algún artículo doctrinal, erróneo en cuanto a sus planteamientos de hecho, por los siguientes motivos:

$1 .^{\circ} \quad$ La voluntariedad a ultranza que mantiene para la cooperación de Planes Provinciales, sólo se puede admitir con matizaciones en la cooperación general del art. 57, pero no en la cooperación formulada para los Planes provinciales, como tuvimos ocasión de exponer.

\footnotetext{
49 TERESA CARBALLEIRA RIVERA: «Sobre algunas Sentencias contradictorias del Tribunal Superior de Xusticia de Galicia en materia de cooperación interprovincial». Revista Xuridica Galega, p. 284.
} 
2. ${ }^{\circ}$ No se toma el concepto último mantenido por la jurisprudencia constitucional, en el sentido como dice la Sentencia 214/87, F.J. 20 que la coordinación supone un cierto poder de dirección consecuencia de la posición de superioridad en que se encuentra el que coordina respecto al coordinado.

3. ${ }^{\circ}$ La alteración de competencias, a que hacen referencia las sentencias:

a) $\mathrm{O}$ no se produce, por tener los municipios y las provincias las mismas competencias, salvo las generales provinciales, puesto que se trata de competencias alternativas, en donde cualquiera de los entes que las posean puede actuarlas.

b) O si se produce, viene autorizada; decimos más, viene obligada por el art. 36.2.b) de la Ley 7/85.

$5 .^{\circ}$ No tiene en cuenta la doctrina del Tribunal Supremo, sobre autonomía provincial y garantía institucional contenida en las Sentencias:

- 23 de junio de 1989, Sala 3. a, Sección 1. ${ }^{\mathrm{a}}$. Ponente, Esteban Alamo.

- 1 de septiembre de 1990, Sala 3. a, Sección $6{ }^{a}$. Ponente, Barrio Iglesias.

En ambas Sentencias, resolviendo conflictos entre la Generalitat y las provincias, se dice sintéticamente:

a) Que el art. 36 de la Ley de Bases de Régimen Local es un haz mínimo de competencias que forman la autonomía provincial, reconocida en el art. 137 de la Constitución Española. La Diputación no puede ser privada de facultades decisorias, porque supondría privarle de la propia autonomía.

b) La Generalitat, aun coordinando ha de respetar ese mínimo competencial.

6. Tampoco podemos admitir como cierta la afirmación que hace la Sentencia de que la subrogación o sustitución es una cuestión inadmisible en nuestro sistema, no tenemos más que leernos el art. 60 de la Ley para darnos cuenta de lo falaz de tal afirmación. 
Además las Sentencias comentadas, dejan sin solución la realización de aquellas obras, que afectan a más de un municipio y son solicitadas por uno de ellos, que obligaría, por la doctrina mantenida por las mismas, a que se hiciese obligatoriamente lo solícitado por el Ayuntamiento correspondiente, sin que se pudiese realizar la obra en otro municipio, por no haberse solicitado.

Por último hemos de decir, que la doctrina mantenida en estas dos últimas sentencias por la Sala, se ve de alguna manera corregida por la misma Sala en Sentencia de 3 de julio de 1992. Ponente, Arrojo Martínez.

A las afirmaciones contenidas en las Sentencias comentadas de que ningún ente coordinado (municipios) puede perder un ápice de sus competencias; al radical principio de que sólo pueden admitirse obras propuestas por los municipios, puesto que lo contrario sería una intromisión intolerable en un régimen de autonomía, las sustituye la teoría de que el ente coordinante (Diputación) podría modificar el Plan (propuestas municipales) en caso de manifiesta ilegalidad.

Para nosotros tiene importancia fundamental que esta Sentencia, rompa con las otras dos últimas y se acerque a las dos primeras. Estas tampoco, como dijimos, conceden plenos poderes a la Diputación, pues basan esa potestad en la cooperación y coordinación, y en definitiva, siguiendo un poco el procedimiento del art. 60, motivando la decisión. Aquella se fundamenta en la manifiesta ilegalidad, con lo cual no coincidimos por los siguientes motivos:

a) La llamada manifiesta ilegalidad, ha dejado de tener efecto alguno en nuestras leyes de régimen local, aunque justo es reconocer que sobre ella giró durante mucho tiempo la tutela del Estado sobre los entes locales, como motivo de la suspensión de acuerdos gubernativos. Hoy, repetimos, tal distinción ha dejado de tener efecto alguno.

b) Al hablar de infracción manifiesta, se hace referencia a un examen de legalidad, no admisible en un régimen de autonomía, por ser incompatible con el mismo, y con el monopolio de examen de legalidad reservado al poder judicial.

\section{Servicios Municipales}

La tercera característica del Plan Provincial, es que su objeto han de ser servicios municipales. Debemos de excluir por lo tanto los supra- 
municipales y las obras y servicios de interés provincial (Sentencias de 27 de noviembre y 5 de diciembre, tantas veces citadas del Tribunal Superior de Xusticia de Galicia).

Cabalmente en relación con el plan, creemos que es de suma importancia la distinción entre servicios municipales y servicios mínimos, por la distinta incidencia, que a nuestro juicio tienen en las potestades de la Diputación en relación con el Plan de Cooperación.

La distinción entre servicios de competencia municipales y servicios mínimos, hace referencia a que estos son un espacio competencial de carácter nuclear (ver nota 26) de la autonomía local. Si el sistema de competencias no es más que una esfera de acción de los distintos entes, a los que se les entrega la potestad para ejercitar esas competencias, en el caso de los servicios mínimos (ver notas 27 y 28), lo que se concede es un Derecho al particular para exigir esa prestación, y por lo tanto una obligación a establecerlo por parte de la Administración.

La propia Ley de Bases de Régimen Local $7 / 85$, en su artículo 18.1.g) dice que entre los Derechos de los vecinos se encuentra el de «exigir la prestación, o en su caso, el establecimiento del correspondiente servicio público, en el supuesto de constituir una competencia municipal propia de carácter obligatorio».

Como garantía del cumplimiento de esa obligación, la Ley de Bases de Régimen Local, art. 36.2.b), impone a las Diputaciones la obligación de asegurar el acceso de la población al conjunto de los servicios mínimos.

Por su parte el art. 26, nos dice que la asistencia de las Diputaciones a los municipios prevista en el art. 36, se dirigirá preferentemente al establecimiento y adecuada prestación de los servicios mínimos.

El reconocimiento jurisprudencial creemos que también es decisivo en la Sentencia ya citada de 25 de Abril de 1989 (Sala 3 ${ }^{\text {a }}$. Sección $1^{\mathrm{a}}$. Ponente, González Navarro), que reconoce a la Ley de Bases de Régimen Local como una norma de inmediata aplicación que señala las competencias obligatorias para los municipios, reconociendo además el derecho de los vecinos a exigir la prestación, y en su caso el establecimiento del correspondiente servicio, en el supuesto de constituir una competencia municipal propia de carácter obligatorio (art. 18). Esta obligación y este derecho que también la Sentencia supone que el Ayuntamiento tiene que cumplir lo que se ha solicitado, lo que implica 
además la obligación de hacer la correspondiente dotación presupuestaria, pues en caso contrario, continúa la Sentencia, el derecho podría no tener efectividad.

Ello nos permite pues afirmar, con González Navarro 50 , que en estos supuestos es posible la sustitución del municipio por la Diputación en la proposición de obras o servicios en el Plan, en igual sentido que lo hacen las Sentencias de 27 de noviembre y 5 de diciembre de 1990 cuando dicen: «En este supuesto de insuficiencia o inconveniente prestación de los servicios municipales mínimos, sintéticamente coincidentes con los llamados a incluírse en los planes, cuando el ámbito de decisión es de la Provincia y puede ajustarse sin la aceptación del municipio.

Ahora bien, creemos que la sustitución tiene sus límites, que podemos, para concluir, enumerar de la forma siguiente:

a) En ningún caso la sustitución puede ser total, sino que ha de referirse a servicios concretos, y como decíamos obligatorios.

b) Creemos que la sustitución es posible en cualquier clase de servicio, si bien cuando no sean de los obligatorios, se necesitará la no oposición del municipio, aunque no haya precedido petición alguna, o se le haya modificado.

c) En los servicios mínimos, la sustitución se produce, incluso en contra de la decisión municipal, como dicen las Sentencias de 27 de noviembre y 5 de diciembre, cuando se hace a través del Plan, y se haga con la consiguiente motivación.

50 F.G. NAVARRO: «Delegación, sustitución y avocación». Tratado de derecho municipal. S.M. MACHADO. Madrid 1989. 
REALA-1993, núm. 260. MARTINEZ FERNANDEZ, FAUSTINO. LA COOPERACION PROVINCIAL A ...

REALA-1993, núm. 260. MARTINEZ FERNANDEZ, FAUSTINO. LA COOPERACION PROVINCIAL A ... 